\title{
Hybrid Plasmids Containing the Pyruvate Dehydrogenase Complex Genes and Gene-DNA Relationships in the 2 to 3 Minute Region of the Escherichia coli Chromosome
}

\author{
By JOHN R. GUEST,* RUTH E. ROBERTS AND PAUL E. STEPHENS \\ Department of Microbiology, Sheffield University, Western Bank, Sheffield S10 2TN, U.K.
}

(Received 16 June 1982; revised 9 August 1982)

\begin{abstract}
A sample of colonies from the Clarke-Carbon ColE1-Escherichia coli DNA plasmid gene bank was screened by conjugation for complementation of the lipoamide dehydrogenase lesion of a deletion strain lacking all components of the pyruvate dehydrogenase complex, $\triangle$ (aroP aceE aceF lpd). Two ColE1-lpd ${ }^{+}$hybrid plasmids were identified: pGS2 (ColE1-ace lpd $d^{+} ; 24 \mathrm{~kb}$ ) and pGS5 (ColE1-lpd $; 14 \mathrm{~kb}$ ). Enzymological studies confirmed that pGS2 expressed all the activities of the pyruvate dehydrogenase complex, whereas pGS5 expressed the lipoamide dehydrogenase and acetyltransferase activities (the latter from a ColEl promoter). These and other plasmids were used to construct a 47 -site (15 enzymes) restriction map for a $24.2 \mathrm{~kb}$ segment of bacterial DNA in the nadC-lpd region. A futher 13 sites (six enzymes) were defined in a $5.4 \mathrm{~kb}$ sub-segment containing the $l p d$ gene. $\lambda$ phage derivatives containing specific fragments were constructed and used in transduction studies which located the ace and $l p d$ genes in a $7.78 \mathrm{~kb}$ sub-segment flanked by $A c c \mathrm{I}$ and $\mathrm{NruI}$ sites.
\end{abstract}

\section{INTRODUCTION}

The pyruvate dehydrogenase complex of Escherichia coli is encoded by three linked genes: ace $E$, pyruvate dehydrogenase or decarboxylase (E1 component); ace $F$, dihydrolipoamide acetyltransferase (E2 component) and $l p d$, lipoamide dehydrogenase (E3 component). The lpd gene product also functions as the $\mathrm{E} 3$ component of the analogous 2-oxoglutarate dehydrogenase multi-enzyme complex. The ace and lpd genes are located at $2.6 \mathrm{~min}$ in the $E$. coli linkage map, very close to nadC (quinolinate ribosyltransferase) and aroP (general aromatic amino acid permease), the gene order being nadC-aroP-aceE-acoF-lpd (Bachmann \& Low, 1980). These genes have recently been cloned in $\lambda$ vectors and the existence of two independent promoters for the ace and lpd genes, each transcribed with the same polarity (clockwise), has been established (Guest \& Stephens, 1980; Guest et al., 1981). The organization and expression of the genes is summarized in Fig. 1.

This paper reports the isolation of ColE1-E. coli DNA hybrid plasmids from the gene bank of Clarke \& Carbon (1976), and the construction of a variety of plasmids and phage derivatives containing specific fragments from the nadC-lpd region. These have facilitated the assembly of a detailed restriction map of the $n a d C-l p d$ region and a further localization of the ace and $l p d$ genes.

\section{METHODS}

Bacteria and phages. A culture containing samples of all the clones in the $E$. coli plasmid gene bank of Clarke \& Carbon (1976) was kindly provided by Dr S. T. Cole. The plasmid-containing strain was JA200 $\left(\mathrm{F}^{+}, t h r-1\right.$ leuB6 trpE5 recA56 thi-1 ara-14 lacYl galK2 galT22 $x y l-5 \mathrm{mtl}-1$ supE44 and the source of $E$. coli DNA in the hybrid plasmids was CS520 (Hfr, glyV50 trpA58 metB1 relA1 spoTI tyrT58?). The recipient used for detecting ColE1-lpd $d^{+}$was JRG746, a streptomycin-resistant $(r p s L)$ and deletion $[\Delta I 8(a r o P-l p d)]$ derivative of K1-1 (metB thy $A$ azi pps ton or $t s x$ ) that was formerly designated $\mathrm{K} \Delta 18 \mathrm{~s}$ (Langley \& Guest, 1977). It contains a deletion, 


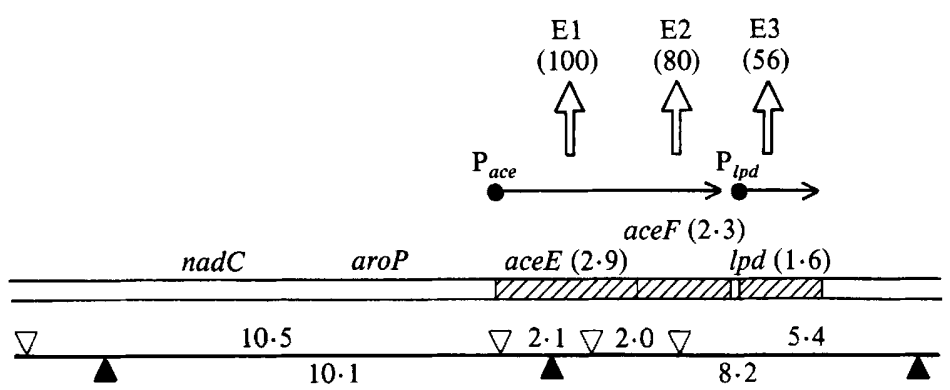

Fig. 1. Diagram showing the gene-protein relationships of the pyruvate dehydrogenase complex of $E$. coli relative to the physical map of the 2.5 to 3.0 min segment of the linkage map that contains the nadC, aroP, aceE, ace $F$ and $l p d$ genes. The approximate positions of the ace and $l p d$ genes relative to the physical map are indicated and their sizes (kb) are based on the sizes of the corresponding products shown in $\mathrm{kDal}$. The transcriptional polarities of two promoters, $\mathbf{P}_{a c e}$ and $\mathbf{P}_{l p d}$ are also indicated. The restriction targets for HindIII $\nabla$ ) and $E c o$ RI $(\mathbf{A})$ are shown and the fragment sizes are in kb.

recently estimated at $6.2 \mathrm{~kb}$ (J. T. Armstrong, unpublished) that extends through the aro $P$, aceE and ace $F$ genes and ends in the $l p d$ gene. The other ace and $l p d$ mutants and deletion strains used in the transduction studies have either been described previously (Langley \& Guest, 1978) or were kindly provided by Dr U. Henning (aceE17, aceF21, aceF25, ace-37 and ace-79; Henning et al., 1964). The strains used for transformation and transfection

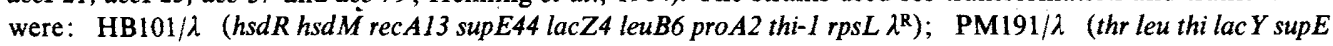
recA $\lambda^{\mathrm{R}}$ ), C600 (thr leu thi lacY supE ton); GM242 (dam-3 recAl sin-2 thr-1 leuB6 proA2 his-4 metB1 lacY1 galK2 ara-14 tsx-33 phi-1 deoB6 supE44 rpsL260; used for preparing pGS20 DNA for digestion with BclI); and ED8654 (met trpR hsdR supE supF).

All the phages used as sources of cloned bacterial DNA and vectors have been described previously (Guest \& Stephens, 1980; Guest \& Shaw, 1981).

Media. The rich medium used for routine subculture and phage propagation was $L$ broth (Lennox, 1955) or LG broth [ $\mathrm{L}$ broth supplemented with $0 \cdot 1 \%(\mathrm{w} / \mathrm{v})$ glucose] for the growth of ace and lpd mutants. This was supplemented with thymine $\left(50 \mu \mathrm{g} \mathrm{ml}^{-1}\right)$ and antibiotics $\left(\mu \mathrm{g} \mathrm{ml}^{-1}\right)$ : streptomycin, 200; ampicillin, 50; tetracycline, 20; and chloramphenicol, 25 or 100, as required. Phage assays were made with BBL medium (Guest \& Stephens, 1980). Minimal medium E (Vogel \& Bonner, 1956) with the carbon sources D-glucose (10 mM) or potassium succinate $(50 \mathrm{mM})$, and supplements of acetate ( $2 \mathrm{mM}$ with glucose, or $4 \mathrm{mM}$ with succinate), succinate ( $2 \mathrm{mM})$, L-amino acids $\left(30 \mu \mathrm{g} \mathrm{ml}^{-1}\right)$, thymine $\left(50 \mu \mathrm{g} \mathrm{ml}^{-1}\right)$ and vitamins $\left(10 \mu \mathrm{g} \mathrm{ml}^{-1}\right)$ were used for nutritional tests and genetic selections. Selective media were sometimes enriched with Difco Bacto nutrient broth $(0 \cdot 2 \%, \mathrm{v} / \mathrm{v})$ and media were solidified with Difco Bacto agar at 15,10 or $6.5 \mathrm{~g} \mathrm{~g}^{-1}$.

Genetic methods. (a) Conjugation. A culture containing representatives of all the clones in the Clarke-Carbon gene bank was screened for $\mathrm{F}^{+}$-mediated conjugation by replica-plating master plates of freshly-grown samples of the donor culture in $\mathrm{L}$ agar on to plates of selective medium spread with approximately $10^{8}$ bacteria from an exponential $\mathrm{LG}$ broth culture of the recipient. The combined presence of $\mathrm{F}^{+}$and ColE1-lpd $d^{+}$activity was detected within 2 to $3 \mathrm{~d}$ and conjugants were purified by streaking to single colonies on the selective medium. The original donor strains were also purified from the active regions of the master plates by streaking to single colonies and retesting for donor activity by the same method.

(b) Transduction. Quantitative transduction tests using $\lambda$ phages were done according to Guest \& Stephens (1980), selecting Ace ${ }^{+}$and $\mathrm{Lpd}^{+}$transductants on appropriate succinate minimal media.

(c) Transformation and transfection. Transformation with plasmid DNA and transfection with phage DNA followed the method of Lederberg \& Cohen (1974) except that the first wash with $\mathrm{CaCl}_{2}$ solution was omitted.

DNA preparation and in vitro manipulation. Plasmid DNA was prepared from cleared lysates by banding in $\mathrm{CsCl}$ gradients containing ethidium bromide (Clewell, 1972; Clewell \& Helinski, 1970). Small scale preparations of plasmid DNA for screening and transformation were made according to Birnboim \& Doly (1979). Phage DNA was prepared from high titre stocks by centrifuging in discontinuous $\mathrm{CsCl}$ gradients followed by phenol extraction (Guest \& Stephens, 1980). Restriction endonuclease digestions and fragment separation and assay by agarose gel electrophoresis were according to Guest \& Stephens (1980) using $\lambda c 11857$ DNA digests as standards. The restriction enzymes were purchased from the Boehringer, BRL, and New England Biolabs, and samples of AspAI (isoschizomeric with BstEII) and EaeAI were kindly provided by $\mathrm{Dr}$ N. L. Brown. Ligation was according to Shaw \& Guest (1982) using phage T4 DNA ligase, a gift from Drs K. and N. E. Murray.

Enzymology. Cultures were grown aerobically in glucose minimal media $(500 \mathrm{ml})$ plus essential supplements, and LG broth ( $100 \mathrm{ml})$, large inocula (1 or $5 \mathrm{ml}$ ) grown in LG broth containing ampicillin or colicin $\mathrm{El}$ to maintain 
the plasmids. The methods for harvesting, preparing ultrasonic extracts and assaying the activities of the pyruvate dehydrogenase complex and its components and the 2-oxoglutarate dehydrogenase complex have been given previously (Langley \& Guest, 1977). Enzyme activities are expressed as $\mu \mathrm{mol}$ substrate transformed (mg protein $)^{-1} h^{-1}$.

\section{RESULTS}

\section{Isolation and properties of ColE1-lpd ${ }^{+}$hybrid plasmids}

A culture grown from representatives of all the clones in the Clarke-Carbon gene bank was screened by conjugation for complementation of the lipoamide dehydrogenase lesion of a deletion strain, JRG746 [ $\triangle($ aroP-aceEF-lpd $)]$. The donors were counterselected by omitting essential growth factors and adding streptomycin to the selective medium. Individual colonies responsible for positive complementation were purified from the donor plates and the conjugants were tested for restoration of the $\mathrm{Lpd}^{+}$and $\mathrm{Ace}^{+}$nutritional phenotypes (Table 1). Two nutritional classes of conjugant were detected : those represented by JRG746/pGS2, had a normal Ace ${ }^{+} \mathrm{Lpd}^{+}$phenotype, and those represented by JRG746/pGS5, which had an Ace ${ }^{-}$ $\mathrm{Lpd}^{+}$phenotype, indicating that the plasmid complemented the lpd but not the ace lesion of JRG746. The donor strains giving rise to these two types of conjugant were recovered and these were JA200/pGS2 $\left(\mathrm{F}^{+}, a c e^{+} l p d^{+} / \mathrm{ColE} 1-a c e^{+} l p d^{+}\right)$and JA200/pGS5 $\left(\mathrm{F}^{+}, a c e^{+} l p d^{+} / \mathrm{ColE} 1-\right.$ $\left.l p d^{+}\right)$.

Enzymology. The specific activities of the pyruvate dehydrogenase complex, its three components and the 2-oxoglutarate complex were assayed in ultrasonic extracts of the conjugants grown in glucose-based minimal media and L broth plus glucose (Table 2). The results confirmed that one plasmid, pGS2, contained functional aceE, aceF and lpd genes, leading to the restoration of overall pyruvate and 2-oxoglutarate dehydrogenase complex activities in the deletion strain. The other plasmid, pGS5, appeared to contain functional aceF and $l p d$ genes, leading to restoration of the 2-oxoglutarate dehydrogenase complex but not the pyruvate complex due to lack of the specific dehydrogenase component (E1). Because ace $F$ is the distal gene of the ace operon (Fig. 1), its expression in the absence of the proximal ace $E$ gene is likely to be from a ColE1 promoter in pGS5. The specific activities in the pGS2-containing strain were not significantly amplified suggesting that expression of the ace and $l p d$ genes could be tightly coupled to metabolic need (despite a high copy number) or that the average plasmid copy number is itself not significantly greater than one. In the case of pGS5 the elevated lipoamide dehydrogenase activity could reflect an increase in gene dosage stemming from the higher copy number that is generally associated with smaller plasmids (see below).

Restriction analysis of the ColE1-lpd ${ }^{+}$hybrid plasmids. The sizes of the plasmids isolated from the original plasmid-containing JA200 strains were estimated by agarose gel electrophoresis as

\section{Table 1. Nutritional characteristics of plasmid-containing strains}

Nutritional tests were performed by streaking dilute suspensions of conjugants and parental strains on minimal media containing glucose or succinate as substrate plus relevant supplement(s) (Glc, glucose; Ac, acetate; Succ, succinate). Growth was scored after $48 \mathrm{~h}$ at $37^{\circ} \mathrm{C}$ as: ++ , very good; + , good; \pm , poor; and -, no growth.

\begin{tabular}{|c|c|c|c|c|c|c|c|}
\hline \multirow[b]{2}{*}{ Strain } & \multirow[b]{2}{*}{ Relevant genotype } & \multicolumn{6}{|c|}{ Growth on test media } \\
\hline & & Glc & $\mathrm{Glc}+\mathrm{Ac}$ & Glc + & $\mathrm{Ac}+\mathrm{Succ}$ & Succ & Succ + Ac \\
\hline $\mathrm{K} 1-1$ & $a c e^{+} l p d^{+}$ & ++ & $+t$ & & ++ & ++ & ++ \\
\hline JRG746 & $\Delta(a c e-l p d)$ & - & - & & + & - & - \\
\hline JRG746/pGS2 & $\Delta(a c e-l p d) / a c e^{+} l p d^{+}$ & ++ & $+t$ & & ++ & ++ & ++ \\
\hline JRG746/pGS5 & $\Delta(a c e-l p d) / l p d^{+}$ & - & ++ & & ++ & - & ++ \\
\hline JRG746/pBR322 & $\Delta(a c e-l p d)$ & - & - & & ++ & - & - \\
\hline JRG746/pGS20 & $\Delta(a c e-l p d) / l p d^{+}$ & - & + & & ++ & - & \pm \\
\hline JRG746/pGS41 & $\Delta(a c e-l p d) / l p d^{+}$ & - & ++ & & ++ & - & + \\
\hline JRG746/pGS42 & $\Delta(a c e-l p d) / l p d^{+}$ & - & ++ & & ++ & - & + \\
\hline JRG746(גG105) & $\Delta(a c e-l p d)\left(\lambda l p d^{+}\right)$ & - & ++ & & ++ & - & + \\
\hline
\end{tabular}


Table 2. Specific activities of pyruvate dehydrogenase complex and components in plasmidcontaining derivatives of an ace-lpd deletion mutant

\begin{abstract}
Ultrasonic extracts of cultures grown on glucose minimal medium supplemented with thiamin, Lmethionine, thymine, acetate and (where necessary) succinate, were prepared and assayed as described in Methods. The specific activities are expressed as $\mu$ mol substrate transformed (mg protein $)^{-1} \mathrm{~h}^{-1}$. Abbreviations: E1, pyruvate dehydrogenase; E2, dihydrolipoamide acetyltransferase; E3, lipoamide dehydrogenase. Similar results were obtained with extracts of organisms grown on LG broth.
\end{abstract}

\begin{tabular}{|c|c|c|c|c|c|c|}
\hline \multirow[b]{2}{*}{ Strain } & \multirow[b]{2}{*}{ Relevant genotype } & \multicolumn{5}{|c|}{ Specific activity } \\
\hline & & $\underset{(a c e E)}{\mathrm{E} 1}$ & $\begin{array}{c}\mathrm{E} 2 \\
(a c e F)\end{array}$ & $\begin{array}{c}\mathrm{E3} \\
(l p d)\end{array}$ & $\begin{array}{c}\text { Pyruvate } \\
\text { dehydrogenase } \\
\text { complex }\end{array}$ & $\begin{array}{c}\text { 2-Oxoglutarate } \\
\text { dehydrogenase } \\
\text { complex }\end{array}$ \\
\hline K $1-1$ & $a c e E^{+} F^{+} l p d^{+}$ & 0.33 & $8 \cdot 1$ & 1.80 & $2 \cdot 50$ & 1.4 \\
\hline JRG746 & $\Delta($ aceEF-lpd $)$ & $<0.02$ & $0 \cdot 3$ & 0.06 & $<0.02$ & $<0.02$ \\
\hline JRG746/pGS2 & $\Delta(a c e E F-l p d) / a c e E^{+} F^{+} l p d^{+}$ & $0 \cdot 26$ & $9 \cdot 0$ & $2 \cdot 20$ & $3 \cdot 40$ & $2 \cdot 0$ \\
\hline JRG746/pGS5 & $\Delta(a c e E F-l p d) / l p d^{+}$ & $<0.02$ & $7 \cdot 2$ & $7 \cdot 10$ & 0.03 & $1 \cdot 3$ \\
\hline JRG746/pBR322 & $\Delta($ aceEF-lpd $)$ & $<0.02$ & 0.5 & 0.04 & $<0.02$ & $<0.02$ \\
\hline JRG746/pGS20 & $\Delta(a c e E F-l p d) / l p d^{+}$ & $<0.02$ & $0 \cdot 3$ & 0.45 & $<0.02$ & $0 \cdot 3$ \\
\hline JRG746/pGS41 & $\Delta($ aceEF-lpd $) / l p d^{+}$ & $<0.02$ & $0 \cdot 3$ & $4 \cdot 10$ & $<0.02$ & 0.9 \\
\hline JRG746/pGS42 & $\Delta($ aceEF-lpd $) / l p d^{+}$ & $<0.02$ & $2 \cdot 3$ & $4 \cdot 50$ & $<0.02$ & 0.7 \\
\hline
\end{tabular}

approximately $24 \mathrm{~kb}$ (pGS2) and $14 \mathrm{~kb}$ (pGS5). Physical maps of both plasmids were constructed by analysing fragments obtained by approximately 100 single, double, triple and sometimes quadruple digestions with different combinations of 15 restriction endonucleases. The relative positions of the restriction targets were readily defined and an unambiguous order was established. Fragments smaller than $0.4 \mathrm{~kb}$ were rarely visible but there was good agreement between the aggregate sizes of fragments obtained in different digests and the total sizes estimated for the two plasmids. The results of this analysis are incorporated into the restriction map of the whole nadC-lpd region (Fig. 2). The segments cloned in pGS2 and pGS5 are indicated together with sufficient information to define the relative polarity of the ColEl vector DNA. The results confirm the positions of the 20 restriction targets already defined by analysing $\lambda$ transducing phages carrying segments of the nadC-lpd region (Guest \& Stephens, 1980). They extend the physical map by approximately $4 \mathrm{~kb}$, in a clockwise direction relative to the $E$. coli linkage map, and they define a further 24 restriction sites, including those for $A c c \mathrm{I}, A s p \mathrm{AI}, \mathrm{ClaI}$, $P s t \mathrm{I}, P v u \mathrm{I}, S a l \mathrm{I}$ and $S p h \mathrm{I}$. The coordinates for the restriction sites, based on zero at $\mathrm{H}_{1}$ in Fig. 2 are (kb): $\mathrm{H}_{1}, 0.00 ; \mathrm{K}_{1}, 0.50 ; \mathrm{A}_{1} / \mathrm{S}_{1}, 1.65 ; \mathrm{R}_{1} 1.80 ; \mathrm{Bg}_{1}, 1.90 ; \mathrm{St}_{1}, 2 \cdot 70 ; \mathrm{Sp}_{1}, 2.82 ; \mathrm{Bg}_{2}, 3.60 ; \mathrm{As}_{1}$, $4.20 ; \mathrm{Ac}_{1}, 4.74 ; \mathrm{B}_{1}, 4.80 ; \mathrm{Sp}_{2}, 7.60 ; \mathrm{Ac}_{2}, 7.64 ; \mathrm{A}_{2}, 8.00 ; \mathrm{Ac}_{3}$ and $\mathrm{Ac}_{4}$, uncertain; $\mathrm{Ac}_{5}, 10.38$; $\mathrm{A}_{3} / \mathrm{S}_{2}, 10.57 ; \mathrm{H}_{2}, 10 \cdot 70 ; \mathrm{B}_{2}, 11.43 ; \mathrm{Pv}_{1}, 11.48 ; \mathrm{A}_{4} / \mathrm{S}_{3}, 11.81 ; \mathrm{R}_{2}, 11.90 ; \mathrm{P}_{1}, 12.22 ; \mathrm{As}_{2}, 12.27$; $\mathrm{Bg}_{3}, 12.55 ; \mathrm{H}_{3}, 12.80 ; \mathrm{Bg}_{4}, 12.90 ; \mathrm{K}_{2}, 13.00 ; \mathrm{P}_{2}, 13 \cdot 10 ; \mathrm{P}_{3}, 13.30 ; \mathrm{C}_{1}, 14.00 ; \mathrm{Ac}_{6}, 14.70 ; \mathrm{H}_{4}$, $14 \cdot 80 ; \mathrm{Sp}_{3}, 15 \cdot 24 ; \mathrm{P}_{4}, 15 \cdot 45 ; \mathrm{R}_{3}, 20 \cdot 20 ; \mathrm{Bg}_{5}, 20.60 ; \mathrm{Ac}_{7} / \mathrm{Sa}_{1}, 20.95 ; \mathrm{Pv}_{2}, 21 \cdot 40 ; \mathrm{K}_{3}, 21 \cdot 90 ; \mathrm{Pv}_{2}$, $22 \cdot 00 ; \mathrm{As}_{3}, 22 \cdot 40 ; \mathrm{A}_{5} / \mathrm{S}_{4}, 22 \cdot 80 ; \mathrm{R}_{4}, 23 \cdot 04 ; \mathrm{St}_{2}, 23 \cdot 14 ; \mathrm{P}_{5}, 23 \cdot 28$.

The analysis supports previous conclusions about the locations of the ace and lpd genes relative to the physical map. Furthermore, it indicates that the ace $F$ gene starts somewhere to the right of the $P$ stI site at $13.3 \mathrm{~kb}\left(\mathrm{P}_{3}\right)$ and that expression of the aceF gene in pGS5 is probably due to coupling to the colicin promoter of ColE1. The latter conclusion is also supported by the observation that the $a c e F$ gene is not expressed in a plasmid incorporating the same segment (see pGS41 below).

\title{
Studies with $p B R 322$ and $p B R 325$ hybrid plasmid derivatives
}

Several plasmids were obtained by sub-cloning specific restriction fragments of the nadC-lpd region into $\mathrm{pBR} 322$ and $\mathrm{pBR} 325$. The aims were to identify precisely the location of the genes, to obtain useful sources of specific fragments and to facilitate the identification of further restriction sites by using small and well-characterized vectors. In this latter respect, sub-cloning enabled the nadC-aroP region to be analysed with the range of enzymes used for the ColE1$l p d^{+}$plasmids, pGS2 and pGS5. It also permitted a more detailed analysis of the large segment of 

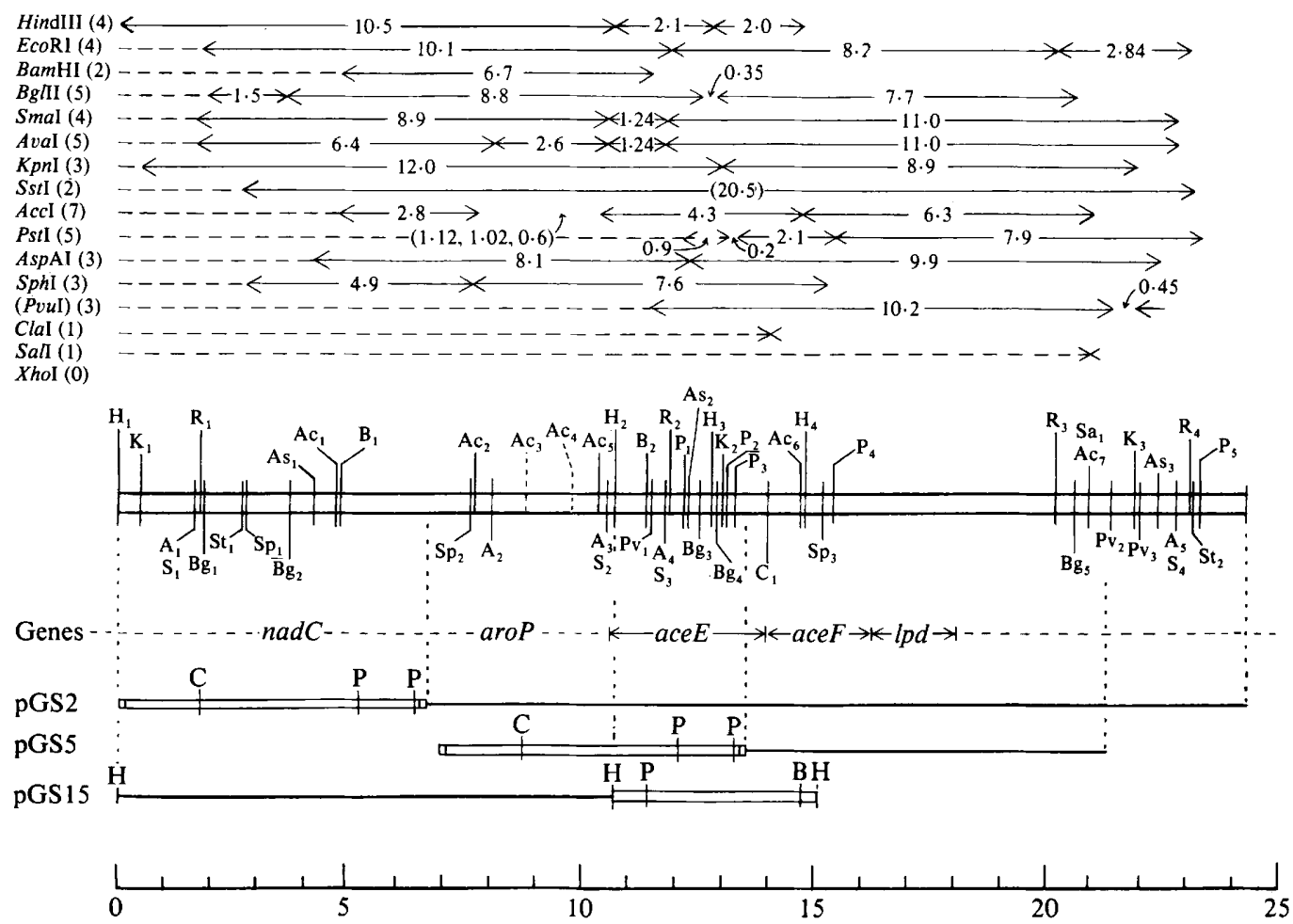

Fig. 2. Restriction map of a $24 \cdot 2 \mathrm{~kb}$ segment of $E$. coli DNA containing the nadC-lpd region of the linkage map. The map is based on studies with three plasmids (pGS2, pGS5 and pGS15), and the segments of cloned bacterial DNA together with sufficient information to define the polarities of the vectors, ColE1 (pGS2 and pGS5) and pBR322 (pGS15), are indicated. The map is drawn to scale (1 division $=1 \mathrm{~kb}$ ) and the coordinates of specific targets relative to the HindIII target $\left(\mathrm{H}_{1}\right)$ are listed in the text. The abbreviations for restriction sites are: A, AvaI; Ac, AccI; As, AspAI; B, BamHI; Bg, BgIII; C, ClaI ; H, HindIII ; K, KpnI ; P, PstI ; Pv, PvuI ; R, EcoRI; S, SmaI ; Sa, SalI ; Sp, SphI ; St, SstI. The sizes and positions of fragments released by single enzymes are shown and all the fragments except the $S s t \mathrm{I}$ fragment (calculated size, $20.5 \mathrm{~kb}$ ) have been analysed following digestion of the three plasmids, or in a few cases, the $\lambda$ transducing phages of Guest \& Stephens (1980). No targets were found for $X h o I$ and the segment of the total map that is missing in pGS2 $\left(\mathrm{H}_{2}\right.$ to $\left.\mathrm{Sp}_{2}\right)$ was not analysed with $P v u I$. The order of the three $A c c$ I fragments released from the $\mathrm{Ac}_{2}$ to $\mathrm{Ac}_{5}$ region was not determined so the precise location of the $\mathrm{Ac}_{3}$ and $\mathrm{Ac}_{4}$ sites is uncertain. The approximate positions of the genes that are known to be encoded in this segment are included together with a line representing their sizes estimated from the sizes of the corresponding gene products (where known).

the lpd region in which no useful restriction sites had been found in previous analyses (Fig. 2). The sources of the sub-cloned fragments and the corresponding vectors used to construct the new plasmids are summarized in Fig. 3.

Nutritional and enzymological studies. Nutritional studies with the deletion strain JRG746 $\Delta($ ace-lpd) after transformation with pBR322 and three plasmid derivatives (pGS20, pGS41 and pGS42) are summarized in Table 1 . In no case was the complete $\mathrm{Ace}^{+} \mathrm{Lpd}^{+}$phenotype restored, but all three derivatives conferred succinate-independence (but not acetate-independence) on glucose medium, consistent with the presence of a functional $l p d^{+}$gene. However, significant differences were observed between pGS20 and the related plasmids, pGS41 and pGS42. The $\mathrm{Lpd}^{+}$phenotype was expressed only partially with pGS20 but more fully with pGS41 and pGS42 and this was particularly apparent on acetate-supplemented succinate medium (Table 1).

Enzymological studies confirmed that overall pyruvate dehydrogenase complex activity was not restored in any of the strains (Table 2). This indicates that the promoter of the ace operon lies to the left of the BamHI site ( $B_{2}$ in Fig. 2). The significant expression of the aceF gene in pGS42 (but not pGS41) suggests that a promoter in the vector is probably responsible. The differences 


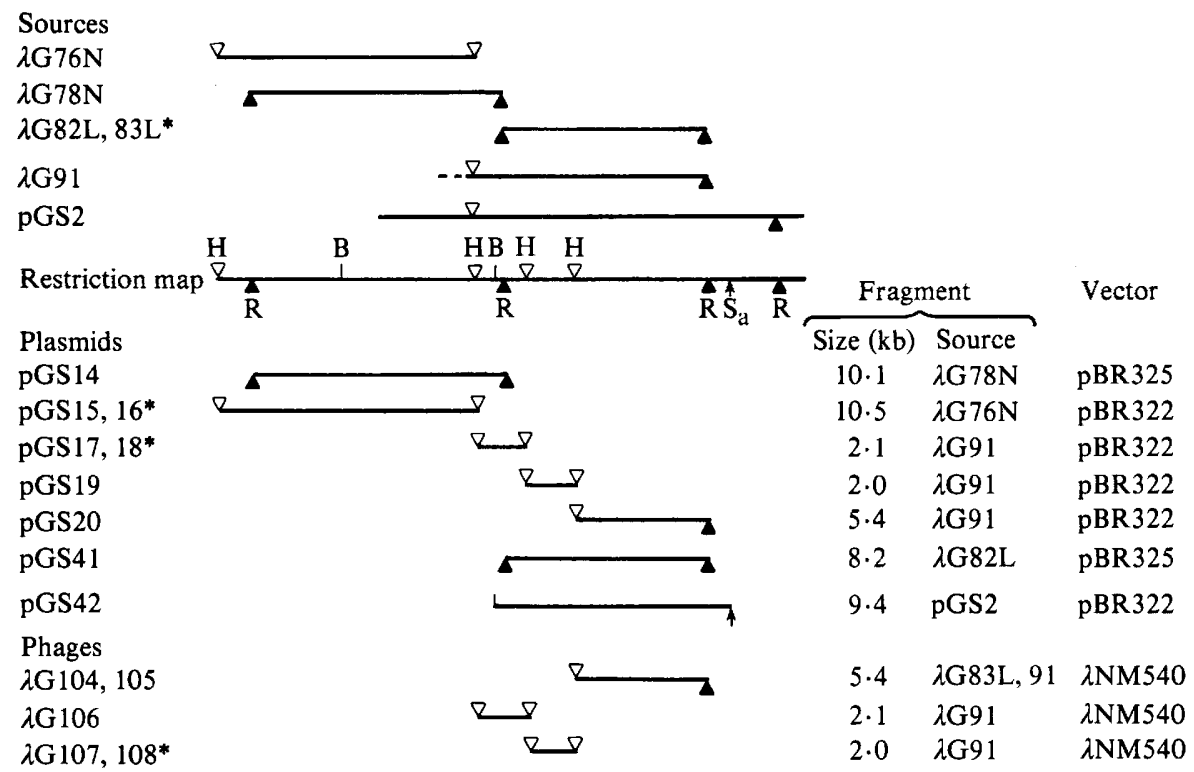

Fig. 3. Plasmids and phages constructed by sub-cloning fragments of the nadC-lpd region. The scale drawing of the restriction map shows the targets for several endonucleases (for abbreviations see legend to Fig. 2) and the sizes of fragments sub-cloned into specific vectors. The sources of the fragments are: pGS2 (this work); transducing phages (Guest et al., 1981). An asterisk denotes that the fragment is cloned with opposite polarities in the corresponding pair of phages or plasmids.

in $l p d^{+}$expression, apparent from the nutritional studies, were confirmed enzymologically (Table 2): lipoamide dehydrogenase was amplified approximately $2 \cdot 5$-fold with pGS41 and pGS 42 but only $25 \%$ of wild-type activity was observed with pGS20. These results are consistent with previous findings that lpd gene expression can be independent of the ace operon and that the $5.4 \mathrm{~kb}$ HindIII-EcoRI fragment $\left(\mathrm{H}_{4}\right.$ to $\mathrm{R}_{3} ; \mathrm{Fig}$. 2) contains the lpd gene (Guest \& Stephens, 1980; Guest et al., 1981). However, the growth properties of the pGS20-containing strain contrast markedly with those of $\lambda \mathrm{G} 105$ lysogens which contain the same cloned fragment and have a fully-restored $\mathrm{Lpd}^{+}$phenotype (Table 1).

Restriction analysis of pGS15 ( adC $\left.^{+}\right)$and pGS20 $\left(l p d^{+}\right)$. The results of the restriction analysis on pGS15, which contains the $10.5 \mathrm{~kb}$ HindIII fragment of a $\lambda$ nadC-aroP phage $(\lambda \mathrm{G} 76 \mathrm{~N})$, are incorporated into the restriction map of the extended nadC-lpd region (Fig. 2). Three further sites were defined, bringing the total for the $24.2 \mathrm{~kb}$ segment of bacterial DNA to 47 restriction sites with 15 different specificities. Their coordinates are included in the list above.

In pGS15 the bacterial DNA is inserted at the HindIII site of pBR322 conferring a Tet ${ }^{\mathrm{s}}$ phenotype and the gene order: amp-aroP-nadC-tet. In pGS16 the same fragment of bacterial DNA is inserted in the opposite orientation (amp-nadC-aroP-tet) and in this case a low but significant resistance to tetracycline is expressed. Presumably the plasmid tet gene is transcribed from a bacterial promoter at the aro $P$ end of the insert. A possible candidate is the ace promoter, which should be close to the critical HindIII target and is known to have the required polarity.

The physical map shows that a $4.75 \mathrm{~kb}$ segment bounded by $P$ st I and EcoRI sites $\left(\mathrm{P}_{4}\right.$ to $\mathrm{R}_{3}$; Fig. 2) is devoid of targets for the commonly used restriction enzymes and previous studies have indicated that the lpd gene is situated in this region (Guest et al., 1981). In order to find useful reference points for nucleotide sequence studies, pGS20, which contains the critical segment in a $5.4 \mathrm{~kb}$ HindIII-EcoRI fragment $\left(\mathrm{H}_{4}\right.$ to $\mathrm{R}_{3} ;$ Fig. 2$)$, was analysed with a further six restriction enzymes. The results are summarized in Fig. 4. In addition to the $S p h \mathrm{I}$ and $P s t \mathrm{I}$ sites $\left(\mathrm{Sp}_{3}\right.$ and $P_{4}$ ), a further 13 sites were identified. The coordinates, based on zero at $H_{1}$ in Fig. 2 are $(\mathrm{kb}): \mathrm{H}_{4}$, $14.80 ; \mathrm{Na}_{1}, 14.85 ; \mathrm{Pu}_{1}, 15.02 ; \mathrm{E}_{1}, 15 \cdot 20 ; \mathrm{Sp}_{3}, 15.24 ; \mathrm{RV}_{1}, 15.38 ; \mathrm{P}_{4}, 15.45 ; \mathrm{Nu}_{1}, 15.66 ; \mathrm{Pu}_{2}$, $16.60 ; \mathrm{Bc}_{1}, 16.62 ; \mathrm{Pu}_{3}, 17 \cdot 00 ; \mathrm{RV}_{2}, 17 \cdot 30 ; \mathrm{Nu}_{2}, 18 \cdot 16 ; \mathrm{Bc}_{2}, 18 \cdot 60, \mathrm{E}_{2}, 19 \cdot 30 ; \mathrm{R}_{3}, 20 \cdot 20$. 


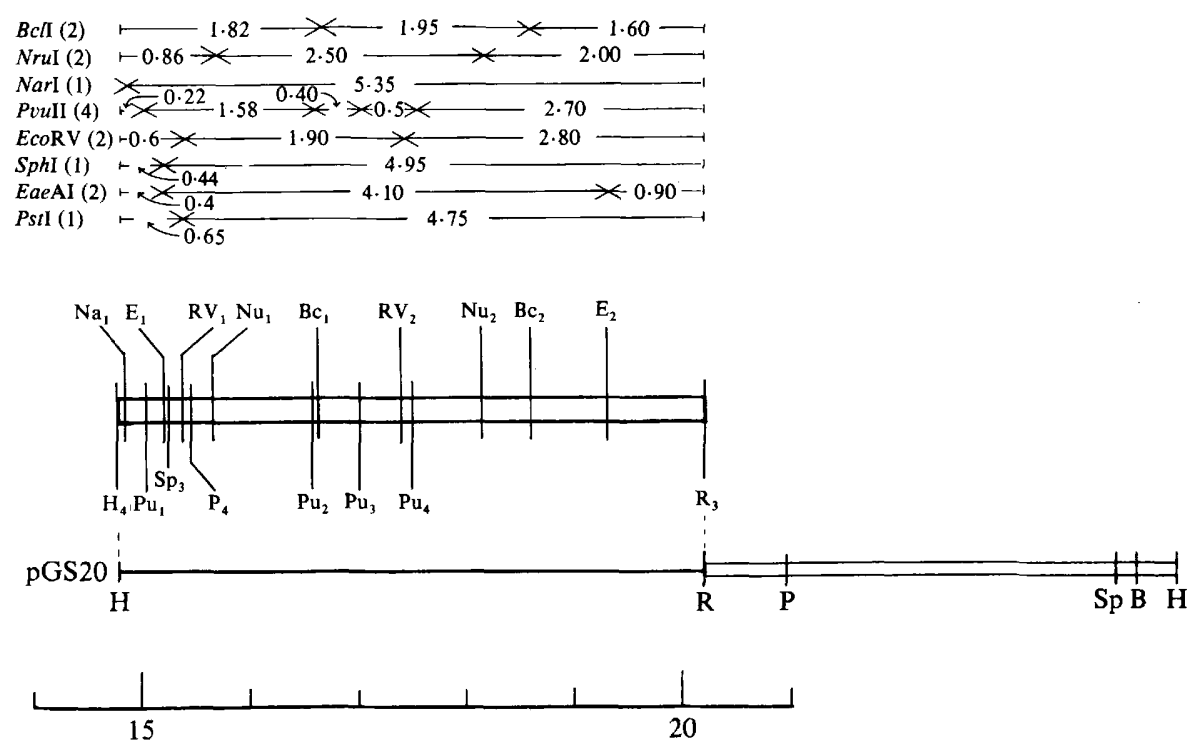

Fig. 4. Scale map showing the positions of restriction sites in the $2.4 \mathrm{~kb}$ HindIII-EcoRI segment of bacterial DNA containing the lpd gene (coordinates 14.80 to $22 \cdot 20, \mathrm{H}_{4}$ to $\mathrm{R}_{3}$ in Fig. 2). The map is based on studies with the derivative of pBR322, pGS20 (Fig. 3) and the position of the fragment relative to representative vector sites is indicated. The scale $(1$ division $=1 \mathrm{~kb})$ originates at the same zero as the map in Fig. 2 and the coordinates of individual sites are listed in the text. Abbreviations: Bc, BcII; E, EaeAI; Na, NarI; Nu, NurI; Pu, PvuII; RV, EcoRV; others are defined in the legend to Fig. 2.

Cleavage at the $B c l$ ll sites was facilitated by preparing plasmid DNA in a Dam- strain. It should also be noted that all the $E c o \mathrm{~V}$ sites may not have been defined because these digests were usually incomplete.

\section{Construction and genetic properties of phages containing segments of the nadC-lpd region of the E. coli chromosome}

In addition to the segments of the nadC-lpd region isolated as specific fragments in HindIII and $E c o$ RI vectors of $\lambda$ in the original cloning studies of Guest \& Stephens (1980), several smaller segments were sub-cloned in $\lambda$ vectors. The phage derivatives served as convenient sources of DNA and were also useful in genetic studies aimed at correlating the physical and genetic maps.

Construction of derivative phages. Phages containing each of the three key fragments that are released from $\lambda a c e-l p d$ phages by HindIII plus $E c o$ RI digestion were constructed as indicated in Fig. 3. Phage $\lambda \mathrm{Gl} 104(\lambda l p d)$ was recovered as an $l p d$ transducing phage with the immunity of the vector phage ( $\lambda \mathrm{NM} 540 ; \mathrm{imm}^{21}$ ) from a ligation mixture containing HindIII digests of two phage DNAs: $\lambda \mathrm{G} 68$ ( $\lambda$ menC $\mathrm{imm}^{21}$; a convenient source of the right arm of the vector) and $\lambda \mathrm{G} 83 \mathrm{~L}$ ( $\lambda l$ lpd $\mathrm{imm}^{\lambda}$; which provides the $5.4 \mathrm{~kb}$ bacterial fragment fused to the left arm of the vector). An identical phage, $\lambda \mathrm{G} 105(\lambda l p d)$, was recovered in the same way from a ligation mixture containing the $5.4 \mathrm{~kb}$ fragment isolated from $\lambda \mathrm{G} 91$ ( $\lambda$ aceEF lpd imm ${ }^{\lambda}$ ) plus EcoRI and HindIII digests of $\lambda N M 540$ to provide left and right vector arms, respectively. Phage $\lambda$ G105 was shown to express the lpd gene product with a leftward transcription polarity relative to the phage genome in post-infection labelling studies (Guest et al., 1981), and the presence of a $\lambda \mathrm{G} 105$ prophage resulted in an $\mathrm{Lpd}^{+}$nutritional phenotype in lysogenic derivatives of strain JRG746 $[\Delta(a c e-l p d)]$ (Table 1). This indicates that the lpd promoter and the lpd structural gene are encoded by the $5.4 \mathrm{~kb} H$ indIII-EcoRI fragment. Phages $\lambda \mathrm{G} 106, \lambda \mathrm{G} 107$ and $\lambda \mathrm{G} 108$ are representative phages recovered from the transfection products of a ligation mixture containing isolated, but unresolved, 2.0 plus $2.1 \mathrm{~kb}$ fragments and HindIII-digested vector DNA $(\lambda N M 540)$. Hybrid phages were enriched in the denser fractions from isopycnic centrifugation 


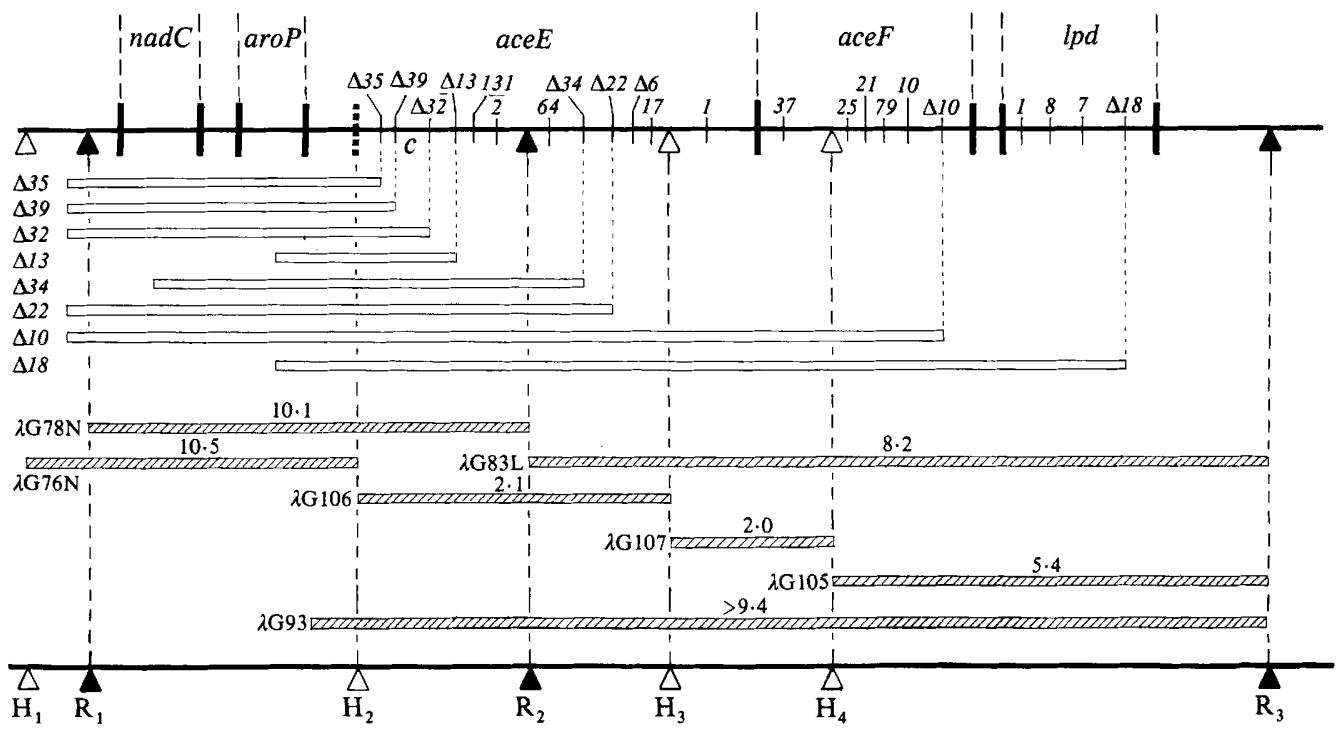

Fig. 5. Map illustrating the physical and genetic structures of the nadC-lpd region of the E. coli chromosome (not to scale). The correlation is based on transductional studies using the hybrid $\lambda$ phages and a collection of 22 aceE, ace $F$ and $l p d$ point and deletion mutants. The sites of the point mutations and relevant deletion end-points are shown and the tentative locations for the ends of the genes are indicated by the vertical bars. The deletions are shown as open bars and the segments of DNA cloned into the corresponding phages are shown as shaded bars. The positions of three restriction targets $\left(R_{2}\right.$, $\mathrm{H}_{3}$ and $\mathrm{H}_{4}$ ) are defined within the ace $E$ and ace $F$ genes, but it is uncertain whether the ace operon starts to the left or right of the HindIII target $\mathrm{H}_{2}$. The $c$ symbolizes the mutation conferring constitutive ace expression (ace ; Langley \& Guest, 1979). For restriction site abbreviations see Fig. 2. Fragment sizes are given in $\mathbf{k b}$.

in $\mathrm{CsCl}$ and individual stocks were identified by restriction analysis. No phages carrying two fragments were recovered, nor were any phages capable of complementing ace mutants found by direct selection.

Genetic studies. The approximate positions of the ace and lpd genes in the restriction map have been defined by a combination of nutritional, enzymological, protein labelling and genetic studies (Guest \& Stephens, 1980; Guest et al., 1981). The genetic studies established that one Eco RI target ( $\mathrm{R}_{2}$ in Fig. 2) is located in the aceE gene between the aceE2 mutation and the end of a deletion, $\Delta 34$. In order to correlate further the physical and genetic maps, the quantitative transductional analysis was extended using phages carrying segments of DNA terminating at four critical sites $\left(\mathrm{H}_{2}, \mathrm{R}_{2}, \mathrm{H}_{3}\right.$ and $\mathrm{H}_{4}$ in Fig. 2) and a collection of 22 different ace and lpd point and deletion mutants (Fig. 5). The phages and their inserts were: $\lambda \mathrm{G} 76 \mathrm{~N}(10 \cdot 5 \mathrm{~kb}$, nadC), $\lambda \mathrm{G} 78 \mathrm{~N}(10 \cdot 1 \mathrm{~kb}$, nadC $), \lambda \mathrm{G} 83 \mathrm{~L}(8.2 \mathrm{~kb}, l p d), \lambda \mathrm{G} 105(5.4 \mathrm{~kb}, l p d), \lambda \mathrm{G} 106(2 \cdot 1 \mathrm{~kb})$ and $\lambda \mathrm{G} 107$ $(2.0 \mathrm{~kb})$. Phage $\lambda \mathrm{G} 93(>9.4 \mathrm{~kb}$, aceEF lpd $)$ was used as a positive control. Ace ${ }^{+}$and $\mathrm{Lpd}^{+}$ transductants were selected on enriched succinate minimal medium after infecting recipient bacteria $\left(2 \times 10^{8}\right)$ with serial dilutions of the transducing phages starting with a multiplicity of infection of 2 . The transduction frequencies ranged from 7000 to $<0.01$ per $10^{6}$ phages and their significance was monitored by estimating reversion frequencies in the same experiments. The results are summarized in the map shown in Fig. 5. They defined the positions of two of the HindIII sites: $\mathrm{H}_{3}$ in the aceE gene and $\mathrm{H}_{4}$ in the ace $F$ gene. Thus, the $5.4 \mathrm{~kb}$ fragment contains part of the ace $F$ gene as well as the entire $l p d$ gene, and the $2.0 \mathrm{~kb}$ fragment contains segments of both the ace $E$ and aceF genes. The position of the EcoRI site $\left(\mathrm{R}_{2}\right)$ was confirmed in the aceE gene but, due to conflicting evidence, the critical HindIII site $\left(\mathrm{H}_{2}\right)$ could not be located unambiguously. For example, phage $\lambda \mathrm{G} 76 \mathrm{~N}$ failed to transduce any of the ace mutants, suggesting that this HindIII site is outside the ace operon (as defined by existing mutations). 
Furthermore, the mutants possessing deletions extending only a short distance into the ace operon were transduced by $\lambda \mathrm{G} 78 \mathrm{~N}$ but not $\lambda \mathrm{G} 76 \mathrm{~N}$, indicating that the deletions extend rightwards beyond the critical HindIII target, $\mathrm{H}_{2}$. However, the deletion strains were not transduced by $\lambda \mathrm{Gl} 106$, suggesting that the region to the left of $\mathrm{H}_{2}$ is essential for ace $^{+}$expression. It is still possible that the ace genes are expressed from within the $2 \cdot 1 \mathrm{~kb}$ fragment if the failure to detect transduction is due to lack of a region of homology near the HindIII site $\left(\mathrm{H}_{2}\right)$ that is needed to facilitate recombination between $\lambda \mathrm{G} 106$ and the deletion recipients. Several ace mutants containing the aceE17, aceF21, aceF25, ace-37 and ace-79 mutations were kindly provided by Dr U. Henning for use in this analysis. The strain bearing the aceE17 mutation (formerly regarded as $a c e F 17$ ) was reclassified as an ace $E$ mutant as a result of the genetic studies (Fig. 5). In addition, the aceE64 mutation was re-located to the right of aceE2 in preference to its former position as the most leftward ace mutation (Henning et al., 1968). All the results were consistent with the marker order defined previously by P1-transduction (Langley \& Guest, 1978).

\section{DISCUSSION}

The isolation and analysis of ColE1-lpd hybrid plasmids from the Clarke-Carbon gene bank confirmed and extended previous studies on the physical structure of the nadC-lpd region of the $E$. coli chromosome and on the location and organization therein of the pyruvate dehydrogenase complex genes. Furthermore, the construction of derivative plasmids and phages carrying specific restriction fragments increased the sensitivity of the analysis and at the same time provided useful sources of DNA and restriction site reference points for subsequent sequence analysis. Some 47 restriction sites for 15 endonucleases were defined in the $24.2 \mathrm{~kb}$ segment of bacterial DNA. A further 13 targets for six additional enzymes were defined in a $5.4 \mathrm{~kb}$ subsegment which lacked convenient restriction targets.

The properties of plasmids pGS2 and pGS5 and $\lambda$ G105 confirmed that the lpd gene is located in the $5.4 \mathrm{~kb}$ HindIII-EcoRI fragment and that it can be expressed independently of the ace genes. Expression of the acetyltransferase component (E2) by pGS5, presumably from a plasmid promoter, indicated that the $a c e F$ gene starts to the right of the PstI site $\left(\mathrm{P}_{3}\right.$ in Fig. 2$)$. This is consistent with the genetic analysis which suggests that the ace $F$ gene overlaps the $2.0 \mathrm{~kb}$ HindIII-HindIII and $5.4 \mathrm{~kb}$ HindIII-EcoRI fragments. The approximate positions of the aceE and $l p d$ genes can also be deduced by estimating the gene sizes from the corresponding products $(a c e E, 2.9 \mathrm{~kb} ; a c e F, 2.3 \mathrm{~kb} ; l p d, 1.6 \mathrm{~kb})$. Thus it can be predicted that the aceE gene starts close to the HindIII site $\left(\mathrm{H}_{2}\right)$, but, as in the genetic analysis, the exact position cannot be defined. Consequently, it remains uncertain whether the ace promoter, or another promoter situated to the left of $\mathrm{H}_{2}$, is responsible for expressing the tet gene in pGS16. Unfortunately, the distribution of restriction sites has hindered the precise location of the ace promoter because the ace genes are not released in a single easily-cloned fragment. Preliminary attempts to clone the adjacent $2 \cdot 1$ and $2.0 \mathrm{~kb}$ HindIII fragments using direct and indirect selections have also been unsuccessful. In view of the uncertain position of the ace promoter, the $A c c$ I-HindIII segment $\left(\mathrm{Ac}_{5}\right.$ to $\mathrm{H}_{2}$, Fig. 2) has been included along with segments in the $\mathrm{H}_{2}$ to $\mathrm{R}_{3}$ region for the sequence analysis that is now in progress. The predicted gene sizes also suggest that the lpd gene ends approximately halfway along the $5.4 \mathrm{~kb}$ HindIII-EcoRI fragment and it is likely that $N r u$ I could be used to remove $2.0 \mathrm{~kb}$ of unwanted DNA from the distal end, in order to simplify the sequence analysis.

A feature of this work is the relatively poor enzyme amplifications (two- to fourfold) associated with cloning the ace and lpd genes into ColE1, pBR322 and pBR325 vectors. This may reflect the operation of a strictly autogenous regulatory mechanism controlling expression of the ace and $l p d$ genes. Such a mechanism, in which transcription of these genes is repressed by the uncomplexed ace and lpd gene products (E1 and E3 components), has been proposed previously (Guest, 1978). However, other possible reasons for poor amplification include plasmid instability and metabolic stress induced by multiple copies of the plasmid (which could lead to the selection of strains with altered plasmid copy number or ace and lpd gene expression). The very poor nutritional and enzymic complementation observed with pGS20 relative to 
comparable plasmids (pGS41 and pGS42) and the $\lambda$ G105 prophage (see Tables 1 and 2) has recently been explained in terms of fragment modification during in vitro manipulation $(\mathrm{H}$. Lewis and P. E. Stephens, unpublished observations). A derivative of pGS41, lacking the 0.9 and $2.0 \mathrm{~kb}$ fragments but retaining the $5.4 \mathrm{~kb}$ EcoRI-HindIII fragment, was isolated from a HindIII digest of pGS41. This plasmid, designated pGS81, has almost the same physical structure as pGS20 and its bacterial insert is derived originally from the same source. However, when tested in a recA derivative of JRG746 [ $\Delta(a c e-l p d)]$, pGS81 and pGS41 fully restored the $\mathrm{Lpd}^{+}$nutritional phenotype and promoted a threefold amplification of lipoamide dehydrogenase, whereas pGS20 failed to affect the nutritional or enzymological phenotypes of the recombination-deficient deletion strain. Nucleotide sequence analysis has also revealed the presence of a single base difference in the lpd genes of pGS20 and pGS41. The poor complementing activity of pGS20 would thus appear to have been $r e c A^{+}$-dependent.

This work was supported by the Science and Engineering Research Council with project grant GR/B35543 (J.R.G.) and a research studentship (P.E.S.).

\section{REFERENCES}

BACHMANN, B. J. \& Low, K. B. (1980). Linkage map of Escherichia coli K-12. Edition 6. Microbiological Reviews 44, 1-56.

BirnboIM, H. C. \& Doly, J. (1979). A rapid alkaline extraction procedure for screening recombinant plasmid DNA. Nucleic Acids Research 7, 1513-1523.

Clarke, L. \& Carbon, J. (1976). A colony bank containing synthetic ColE1 hybrid plasmids representative of the entire $E$. coli genome. Cell 9, 91-99.

Clewell, D. B. (1972). Nature of ColE1 plasmid replication in Escherichia coli in the presence of chloramphenicol. Journal of Bacteriology 110, 667676.

Clewell, D. B. \& Helinski, D. R. (1970). Properties of a supercoiled deoxyribonucleic acid-protein relaxation complex and strand specificity of the relaxation event. Biochemistry 9, 4428-4440.

GUEST, J. R. (1978). Aspects of the molecular biology of lipoamide dehydrogenase. Advances in Neurology 21, 219-244.

Guest, J. R. \& Shaw, D. J. (1981). Molecular cloning of menaquinone biosynthesis genes of Escherichia coli K12. Molecular and General Genetics 181, 379383.

Guest, J. R. \& Stephens, P. E. (1980). Molecular cloning of the pyruvate dehydrogenase complex genes of Escherichia coli. Journal of General Microbiology 121, 277-292.

Guest, J. R., Cole, S. T. \& Jeyaseelan, K. (1981). Organization and expression of the pyruvate dehydrogenase complex genes of Escherichia coli K12. Journal of General Microbiology 127, 65-79.

Henning, U., Herz, C. \& Szolyvay, K. (1964). Polarisation und Disproportionalität der Synthese von Enzymkomponenten des Pyruvat-Dehydrogenase-Komplexes als Mutationsfolge in Escherichia coli K12. Zeitschrift für Vererbungslehre 95, 236-259.

Henning, U., Dietrich, J., MurRay, K. N. \& DePPE, G. (1968). Regulation of pyruvate dehydrogenase synthesis: substrate induction. In Molecular Genetics, pp. 223-236. Edited by H. G. Wittmann \& H. Schuster. Berlin: Springer-Verlag.

Langley, D. \& Guest, J. R. (1977). Biochemical genetics of the $\alpha$-keto acid dehydrogenase complexes of Escherichia coli K12: isolation and biochemical properties of deletion mutants. Journal of General Microbiology 99, 263-276.

LANGLEY, D. \& Guest, J. R. (1978). Biochemical genetics of the $\alpha$-keto acid dehydrogenase complexes of Escherichia coli $\mathrm{K} 12$ : genetic characterization and regulatory properties of deletion mutants. Journal of General Microbiology 106, 103-117.

LederberG, E. M. \& CoHEN, S. N. (1974). Transformation of Salmonella typhimurium by plasmid deoxyribonucleic acid. Journal of Bacteriology 119, $1072-1074$.

LENNOX, E. S. (1955). Transduction of linked genetic characters of the host by bacteriophage P1. Virology 1, 190-206.

Shaw, D. J. \& Guest, J. R. (1982). Amplification and product identification of the fnr gene of Escherichia coli. Journal of General Microbiology 128, 2221-2228.

VOGEL, H. \& BONNER, D. M. (1956). A convenient growth medium for Escherichia coli and some other micro-organisms. Microbial Genetics Bulletin 13, 4344. 